\title{
Size Effect of Graphene Quantum Dots on Photoluminescence
}

\author{
Ziyi Liu ${ }^{1,+}$, Fei Li ${ }^{1, \dagger}$, Yi Luo ${ }^{1}$, Ming Li ${ }^{1, *}$, Guanghui Hu ${ }^{1}$, Xianjuan Pu ${ }^{2, *}$, Tao Tang ${ }^{1}{ }^{(}$, Jianfeng Wen ${ }^{1}$, \\ Xinyu $\mathrm{Li}^{1}$ and Weitao $\mathrm{Li}^{3, *(1)}$
}

1 College of Science, Guilin University of Technology, Guilin 541004, China; liuziyi0917@163.com (Z.L.); m17753101516@163.com (F.L.); adam2513@163.com (Y.L.); hu-guanghui-rm@ynu.jp (G.H.); tangtao@glut.edu.cn (T.T.); wjfculater@163.com (J.W.); lixinyu5260@163.com (X.L.)

2 Shanghai Applied Radiation Institute, School of Environmental and Chemical Engineering, Shanghai University, Shanghai 200444, China

3 Textile and Garment Industry of Research Institute, Zhongyuan University of Technology, Zhengzhou 450007, China

* Correspondence: liming928@163.com (M.L.); xjpu0601@shu.edu.cn (X.P.); liweitao@zut.edu.cn (W.L.)

+ These authors contributed equally to this work.

check for updates

Citation: Liu, Z.; Li, F.; Luo, Y.; Li, M.; Hu, G.; Pu, X.; Tang, T.; Wen, J.; Li, X.; Li, W. Size Effect of Graphene Quantum Dots on Photoluminescence. Molecules 2021, 26, 3922. https:// doi.org/10.3390/molecules26133922

Academic Editor: Minas M. Stylianakis

Received: 19 May 2021

Accepted: 23 June 2021

Published: 26 June 2021

Publisher's Note: MDPI stays neutral with regard to jurisdictional claims in published maps and institutional affiliations.

Copyright: (c) 2021 by the authors. Licensee MDPI, Basel, Switzerland. This article is an open access article distributed under the terms and conditions of the Creative Commons Attribution (CC BY) license (https:// creativecommons.org/licenses/by/ $4.0 /)$.

\begin{abstract}
High-photoluminescence (PL) graphene quantum dots (GQDs) were synthesized by a simple one-pot hydrothermal process, then separated by dialysis bags of different molecular weights. Four separated GQDs of varying sizes were obtained and displayed different PL intensities. With the decreasing size of separated GQDs, the intensity of the emission peak becomes much stronger. Finally, the GQDs of the smallest size revealed the most energetic PL intensity in four separated GQDs. The PL energy of all the separated GQDs shifted slightly, supported by density functional theory calculations.
\end{abstract}

Keywords: graphene quantum dots; size effect; photoluminescence

\section{Introduction}

Recently, luminescent carbon materials have received considerable attention, including carbon nanotube [1,2], carbon quantum dots [3,4], reduced graphene oxide quantum dots [5], graphene oxide [6], and graphene quantum dots (GQDs) [7]. Compared with traditional semiconductor quantum dots, such as $\mathrm{CdX}(\mathrm{X}=\mathrm{S}, \mathrm{Se})$ and $\mathrm{PbS}$, GQDs provide various advantages, such as more environment-friendly, low-cost, easy-to-prepare, relatively stable chemical internees and strong luminescence. In particular, GQDs, as a zerodimension graphene material, has the characteristics of graphene and unique quantum confinement effects and edge effects [8-10]. These proprieties endow GQDs with stable fluorescence and adjustable bandgap [11-13]. Based on the above excellent feature, GQDs could be applied in multiple fields, such as photovoltaic devices [14], catalysis [15-22], solar cells [23,24], sensing [25,26], drug delivery [27], and cell imaging [28-31]. The hydrothermal method is a commonly used method for preparing GQDs. Pan et al. first prepared GQDs by chemically cutting graphene nanosheets through acid and a hydrothermal environment $[10,32]$. But the arrangement of the GQD prepared by this method is not regular. Dong et al. used the acid exfoliation method to prepare graphene quantum dots by chemically oxidizing carbon black (CB) in $\mathrm{HNO}_{3}$ under reflux conditions. However, it is difficult to remove excess oxidant (for example, $\mathrm{HNO}_{3}$ ) from the solution [33]. Various methods for preparing GQDs have been reported $[34,35]$. The fluorescences of GQDs synthesized by different methods mostly display blue, green, and yellow colors. Their photoluminescence (PL) properties have been studied [36,37]. To adjust the bandgap and electronic density effectively, strengthen chemical activity, increase the quantum yield (QY), and expand the practical application of GQDs, a large number of published research studies have focused on modifying GQDs by doping heteroatoms [38], for instance, nitrogen and 
sulfur [39], chlorine [40], and fluorine [7]. However, the effect of GQDs with different sizes on PL intensity has not been thoroughly investigated.

We found that there are few studies on whether the PL emission intensities of GQDs of different sizes are different. In order to fill the gap in this regard, we synthesized GQDs by a simple one-step hydrothermal method and then obtained four separated GQDs using dialysis bags with different molecular weights. The dimension changes and PL properties of the separated GQDs were investigated. Furthermore, the relationship between the size of the obtained GQDs and their PL energy shift is discussed. Overall, DFT calculation was used to illustrate the PL energy shift.

\section{Experimental Section}

\subsection{Synthesis of GQDs}

GQDs were prepared by a simple, green, bottom-up hydrothermal method [41]. Briefly, $1 \mathrm{~g}$ of pyrene was added to $80 \mathrm{~mL}$ of $65-68 \%$ nitric acid, then refluxed and stirred for $12 \mathrm{~h}$ at $80{ }^{\circ} \mathrm{C}$. After cooling to room temperature, the product was diluted with $200 \mathrm{~mL}$ of distilled water (DI) and filtered by a $0.22 \mu \mathrm{m}$ filter membrane to remove the excess acid, then dissolved in $150 \mathrm{~mL}$ of $0.0125 \mathrm{M}$ aqueous $\mathrm{NaOH}$ solution by ultrasound to adjust the $\mathrm{pH}$ value to 11 . Then the ultrasonic suspension was transferred to a Teflon autoclave and was heated at $180{ }^{\circ} \mathrm{C}$ for $12 \mathrm{~h}$. Next, after cooling to room temperature, the obtained product was filtered through a $0.22 \mu \mathrm{m}$ filter membrane to remove the insoluble product. To obtain the GQDs of different sizes, the GQD solution was separately dialyzed with 14,000, 7000, 3500, and 1000 Da molecular weight dialysis bags successively.

\subsection{Computational Details}

All calculations were performed using the Vienna Ab initio Simulation Package (VASP) $[42,43]$. The projector augmented-wave (PAW) potentials $[44,45]$ with an energy cutoff of $800 \mathrm{eV}$ were used for the plane-wave basis set. The generalized gradient approximation (GGA) in the form of the Perdew-Burke-Ernzerhof (PBE) functional was employed [46]. In this work, two different-sized systems of the armchair- and zigzag-edged GQDs were modeled (hexagonal cell). To minimize the artificial interactions due to periodic boundary conditions, each GQD was separated by a vacuum of $\sim 15 \AA$. The Brillouin zone was sampled by $3 \times 3 \times 1$ Monkhorst-Pack k-point grids. All atoms were relaxed until the residual forces on each atom were less than $0.01 \mathrm{eV} / \AA$.

\subsection{Characterization}

Transmission electron microscopy (TEM) was carried out on a JEM-2100F (JEOL, Japan) electron microscope. Samples were prepared by placing a drop of dilute aqueous dispersion of GQDs on the surface of a copper grid. Powder X-ray diffraction (XRD) spectra were collected on a Rigaku D/Max 2550 diffractometer within $5^{\circ}-80^{\circ}$ ( 2 theta). X-ray photoelectron spectroscopy (XPS) measurements were made on Escalab 250XI with mono Al K $\alpha$ radiation $(\mathrm{h} v=1486.6 \mathrm{eV})$. Raman spectra were recorded on a laser confocal Raman spectrometer (Renishaw inVia) with $514 \mathrm{~nm}$ incident radiation. The photoluminescence spectra (PL) and photoluminescence excitation (PLE) spectra were recorded using a fluorescence spectrophotometer (Agilent Technologies, Cary Eclipse, Australia) at a sample concentration of $0.1 \mathrm{mg} \cdot \mathrm{mL}^{-1}$. UV-VIS absorption spectra were recorded on a PerkinElmer Lambda 750 spectrophotometer at a sample concentration of $0.1 \mathrm{mg} \cdot \mathrm{mL}^{-1}$. Fourier-transform infrared (FTIR) spectra were recorded using an IRAffinity-1S spectrometer (KBr pellet). Unless otherwise specified, the GQDs (the GQDs dialyzed with a dialysis bag of $1000 \mathrm{Da}$ ) with the best optical performance were selected for various characterizations.

\section{Results and Discussion}

The TEM and high-resolution TEM images of four separated GQDs dialyzed with dialysis bags of 14,000, 7000, 3500, and 1000 Da molecular weights are shown in Figure 1a-h The separated GQDs are well dispersed with a uniform size distribution, whose average 
lateral sizes are about 10.33, 9.33, 8.42, and $6.53 \mathrm{~nm}$, respectively (insets in Figure 1a-h). This indicates that the size of the separated GQDs obtained by dialysis with different molecular weights of dialysis bags is different. As the molecular weights of the dialysis bags decreased, the size of the obtained GQDs also reduced. High-resolution TEM images also show crystalline GQDs with a lattice measurement of $0.203 \mathrm{~nm}$, which coincide with the graphene (002) plane [18]. The real-space images and their fast Fourier transform (FFT) patterns (insets in Figure 1e-h) with a hexagonal honeycomb structure demonstrate that the GQDs are nearly defect-free graphene single crystals.
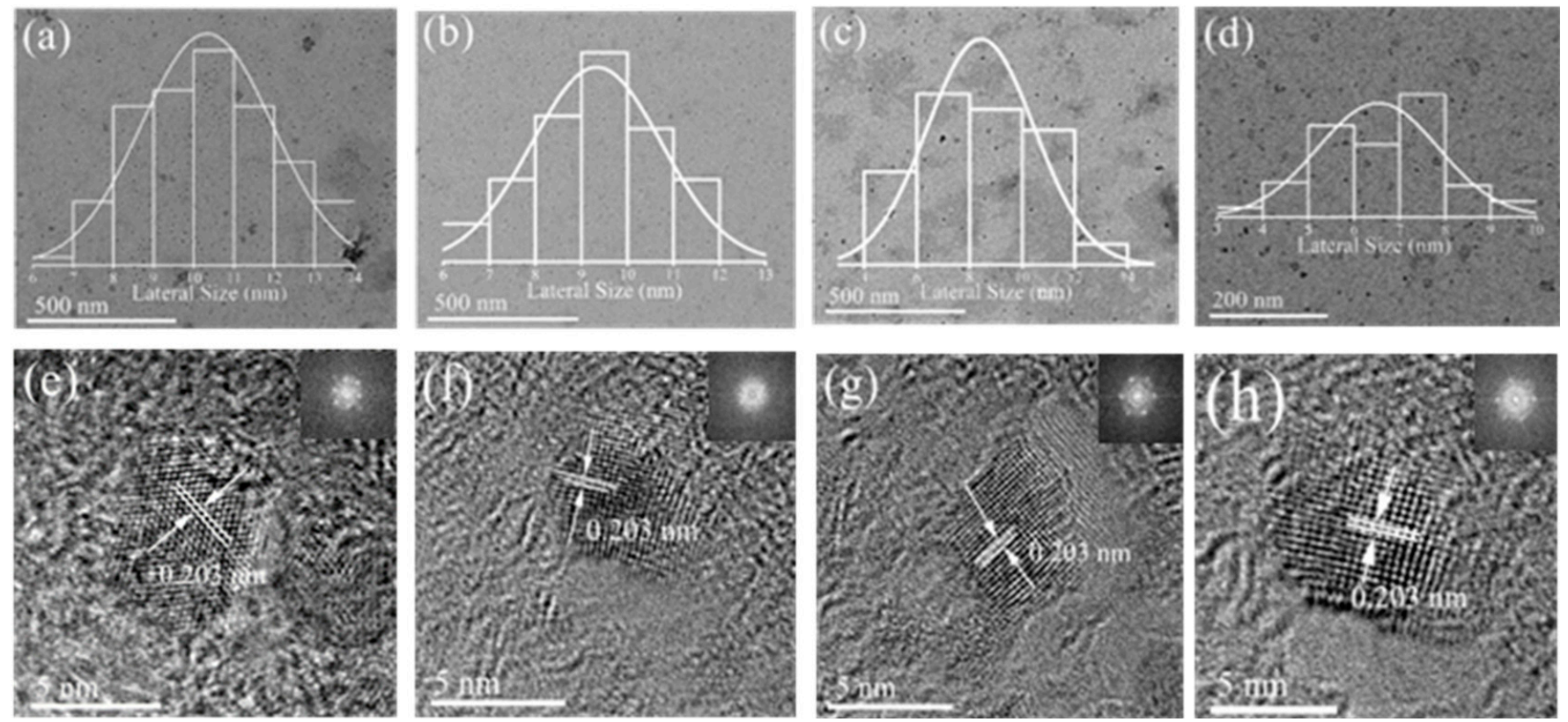

Figure 1. TEM images of four separated GQDs dialyzed with dialysis bags of 14,000 Da (a), $7000 \mathrm{Da}(\mathbf{b}), 3500 \mathrm{Da}(\mathbf{c})$, and $1000 \mathrm{Da}$ (d) molecular weights; insets are corresponding lateral size distributions. High-resolution TEM images of four separated GQDs dialyzed with dialysis bags of 14,000 Da (e), $7000 \mathrm{Da}$ (f), $3500 \mathrm{Da}$ (g), $1000 \mathrm{Da}$ (h) molecular weights; insets are corresponding FFT patterns.

To understand their structure, various spectral characterizations were used. Figure 2a shows XRD patterns of GQDs. We can observe a typical peak (002) at $2 \theta=26.5^{\circ}$, and the interlayer spacing is $3.34 \AA$, which is identical to that of graphene [41,47]. FTIR spectroscopy was also revealed to be a further characteristic of samples. As shown in the FTIR spectra in Figure $2 \mathrm{~b}$, a distinct peak at $1590 \mathrm{~cm}^{-1}$ corresponds to the vibration of $\mathrm{C}=\mathrm{C}$ bonds, and a broad vibration at about $3430 \mathrm{~cm}^{-1}$ for the $\mathrm{O}-\mathrm{H}$ bonds $[41,47,48]$. The $\mathrm{O}-\mathrm{H}$ peak is mainly given credit for the hydroxyl of the obtained GQDs and can be confirmed by the strong vibration of $\mathrm{C}=\mathrm{OH}$ at about $1270 \mathrm{~cm}^{-1}$. The obvious peak at about $870 \mathrm{~cm}^{-1}$ is attributed to the vibration of $\mathrm{C}-\mathrm{H}$ [48].

To further determine the component of GQDs, XPS measurement was employed. The XPS full spectra (Figure 3a) of the four separated GQDs obtained by different molecular weights of dialysis bags show that the strong peaks at approximately $284 \mathrm{eV}$ (C 1s) and $533 \mathrm{eV}(\mathrm{O} 1 \mathrm{~s})$ exist in all GQDs, as well as a week peak from impurity $\mathrm{Na}^{+}$. The highresolution spectrum of the $C 1$ s reign of GQDs (Figure $3 b$ ) shows the strong peak of $C=C$ at $284.8 \mathrm{eV}$ and another distinguishable peak of $\mathrm{COOH}$ at $288.1 \mathrm{eV}$. The high-resolution $\mathrm{O} 1 \mathrm{~s}$ spectrum (Figure 3c) reveals the existence of the peak of $\mathrm{O}-\mathrm{H}$ at $531.4 \mathrm{eV}$. The highresolution $\mathrm{C} 1 \mathrm{~s}$ and $\mathrm{O} 1 \mathrm{~s}$ spectra of the other three separated GQDs obtained by dialysis bags of 14,000, 7000, and 3500 Da molecular weights are shown in Figure S1. The data of XPS display that the obtained 1,3,6-trinitropyrene by water bath reaction synthesized GQDs by obliterating the $\mathrm{NO}_{2}$ group under a strong alkaline condition. The bonding position between the hydroxyl group and the single-crystalline GQD lattice is most likely 
at the edge rather than that at the basal plane. This unique edge functionalization property will not bring out any defects in the graphene basal plane, which is different from other functionalizations viewed in graphene oxide $[41,49,50]$ and defective GQDs obtained by other methods [32-52].
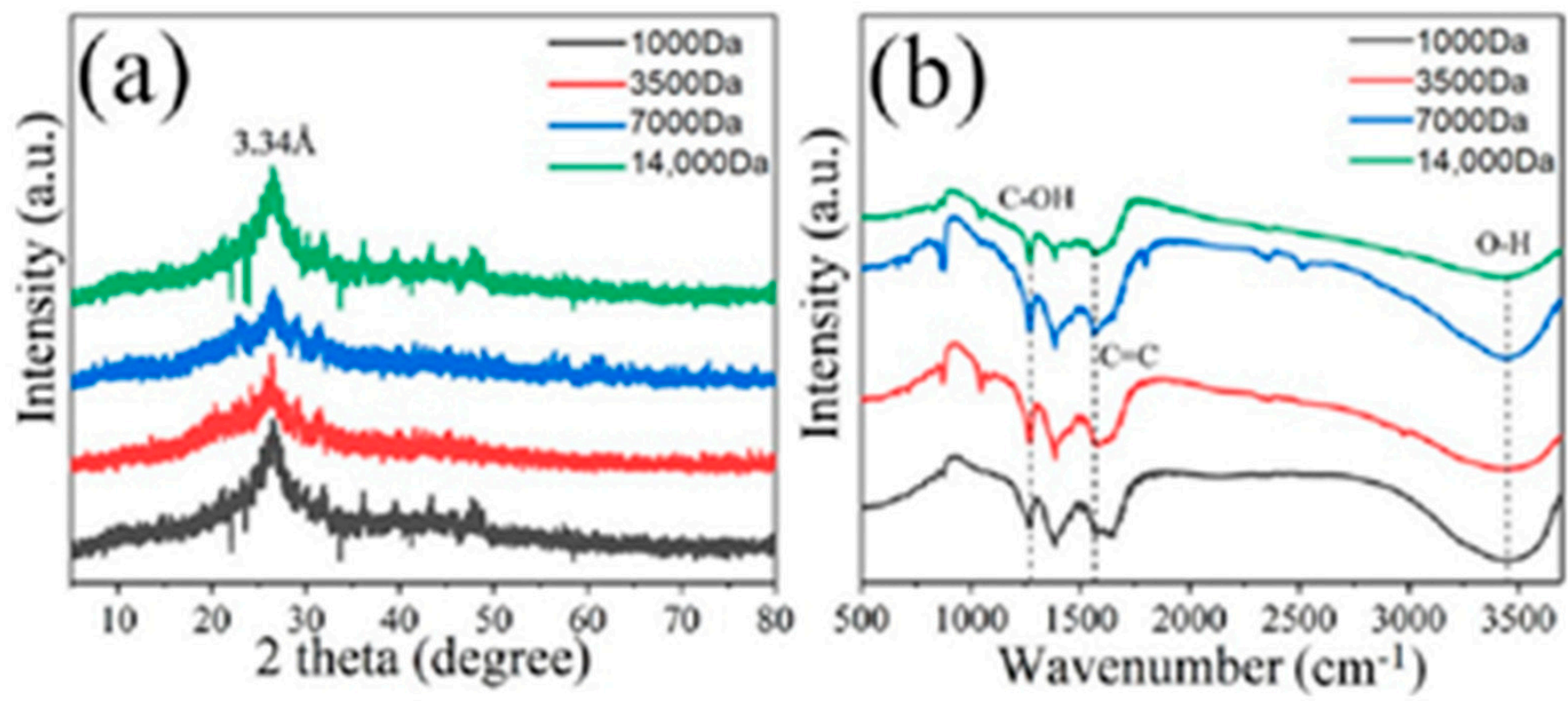

Figure 2. XRD patterns (a) and FTIR spectra (b) of four separated GQDs.
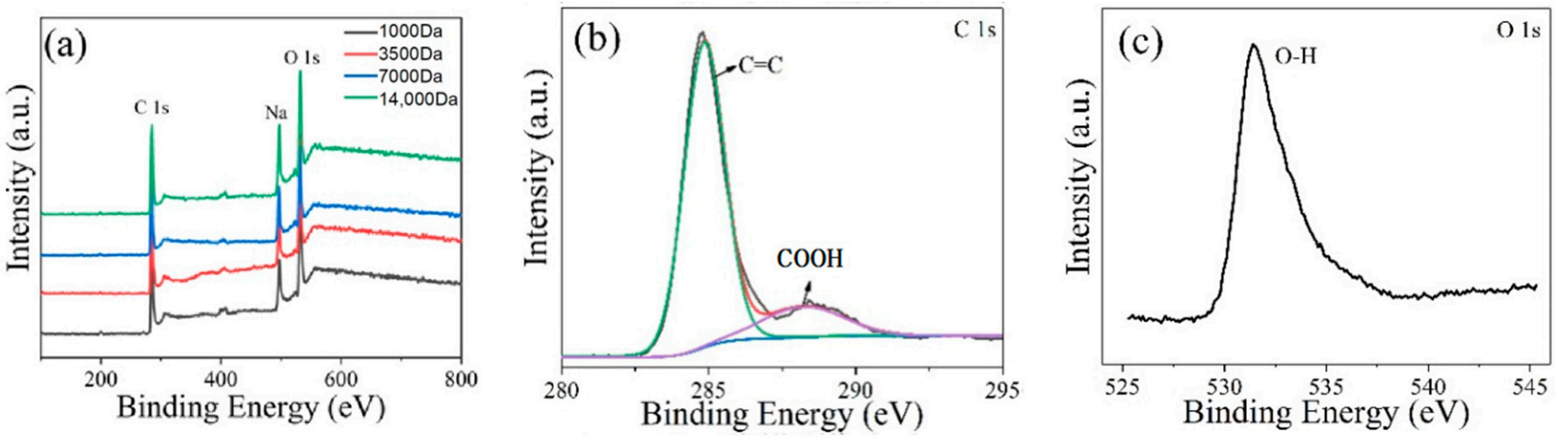

Figure 3. (a) XPS full spectra of four separated GQDs. High-resolution C 1s (b) and O 1s spectra (c) of GQDs dialyzed with a dialysis bag of $1000 \mathrm{Da}$ molecular weight.

For comparison, the Raman spectra of the four separated GQDs obtained with dialysis bags of different molecular weights were also measured. As shown in Figure 4, as the size of the GQD molecular decreases, the G and D peaks of the Raman spectrum become more and more obvious. Only GQDs obtained from dialysis bags with a molecular weight of 1000 Da have obvious G and D peaks. This is also closest to the characteristic values of a single-layer graphene. We generally use the ratio of peak $D$ to peak $G$ to indicate the density of defects in graphene. The greater the ratio, the greater the degree of defects, and vice versa. It can be seen from the Raman spectrum of the sample (Figure 4) that the $G$ peak is always slightly higher than the D peak, so $I_{D} / I_{G}$ is less than 1 , as shown in Table 1 . This is consistent with what was mentioned in the previous article; that is, GQD is almost a defect-free single crystal of graphene. 


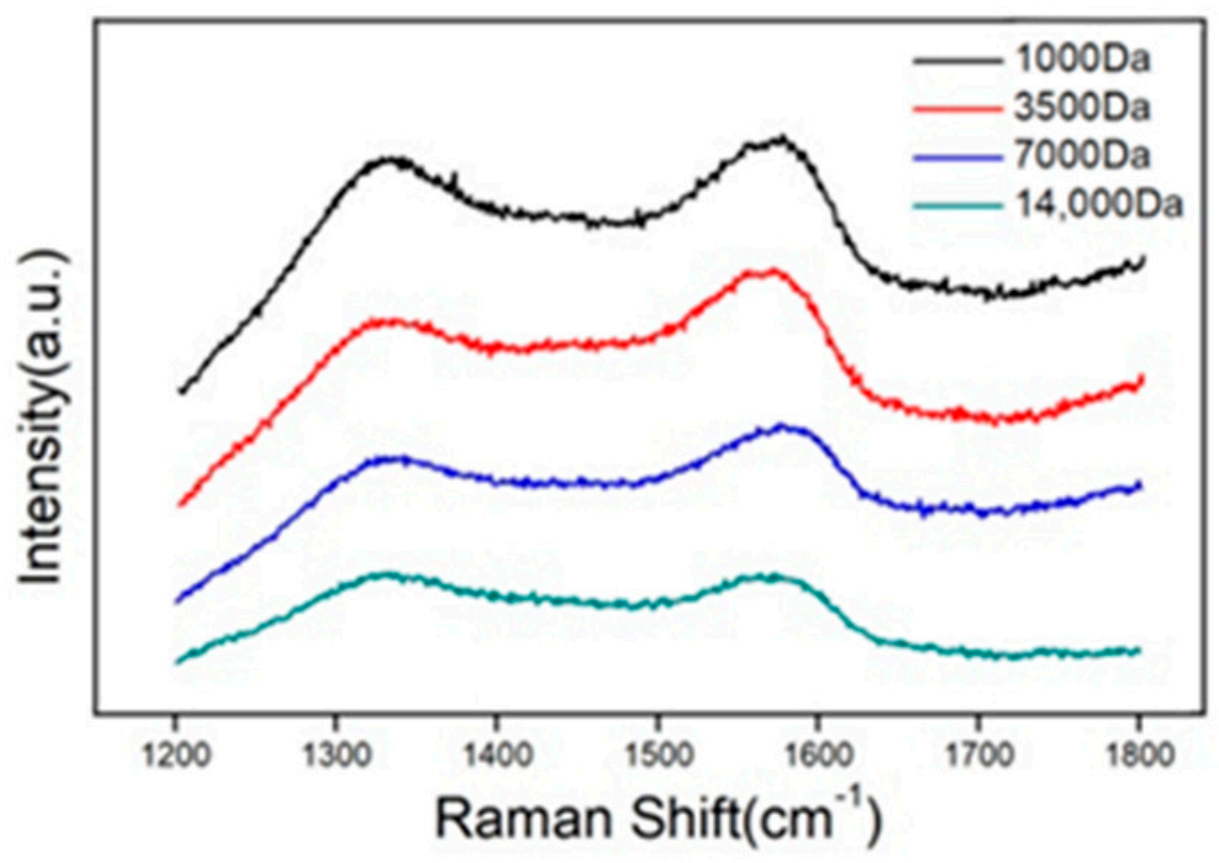

Figure 4. Raman spectra of the four separated GQDs.

Table 1. D and G peak frequencies of the GQD samples obtained from dialysis bags of different molecular weights.

\begin{tabular}{cccccc}
\hline Samples & D Peak Position $\left(\mathbf{c m}^{-1}\right)$ & $\boldsymbol{I}_{\boldsymbol{D}}$ & G Peak Position $\left(\mathbf{c m}^{-1}\right)$ & $\boldsymbol{I}_{\boldsymbol{G}}$ & $\boldsymbol{I}_{\boldsymbol{D}} / \mathbf{I}_{\boldsymbol{G}}$ \\
\hline $1000 \mathrm{Da}$ & 1333.5 & $89,594.1$ & 1576.61 & 91,445 & 0.98 \\
$3500 \mathrm{Da}$ & 1343.29 & $37,244.3$ & 1581.99 & $39,994.2$ & 0.93 \\
$7000 \mathrm{Da}$ & 1342.23 & $44,510.4$ & 1575.87 & $47,180.2$ & 0.94 \\
$14,000 \mathrm{Da}$ & 1333.78 & $34,741.8$ & 1572.8 & $34,708.5$ & 1.00 \\
\hline
\end{tabular}

To explore the optical properties of the four separated GQDs with varying sizes, the UV-VIS absorption and PL spectra were demonstrated. GQDs are highly soluble in DI water. The as-prepared GQD aqueous dispersion exhibited green fluorescence under irradiation with $365 \mathrm{~nm}$ UV light (inset in Figure 5a), which is consistent with the other three separated GQDs obtained by dialysis bags of 14,000, 7000, 3500 Da molecular weights (inset in Figure S2a-c). As shown in Figure 5a, the GQDs exhibit two distinct excitonic absorption bands at about 365 and $490 \mathrm{~nm}$ in the UV-VIS absorption spectrum, which is similar to the GQDs synthesized by hydrothermal method [33]. The two absorption peaks can be assigned to the $\pi-\pi^{*}$ and $n-\pi^{*}$ transitions between the oxygen-/nitrogencontaining groups and $\mathrm{sp}^{2}$ domains $[53,54]$. As the size of GQDs increased, the intensity of the absorption peak became weaker (Figure $5 \mathrm{a}$ and Figure S2a-c). This means that we can increase the absorption of ultraviolet light by reducing the size of the GQDs.

As displayed in Figure $5 b$ and Figure S2d-f, the maximum PL wavelengths of the four separated GQDs were non-change-excited at different wavelengths, exhibiting their excitation-independent property. When the four separate GQDs are irradiated with different wavelengths of ultraviolet light, the positions of their PL emission peaks are slightly different, which means that we can control the fluorescence color of the GQDs by changing the excitation wavelength. The emission peak of GQDs was observed at about $530 \mathrm{~nm}$. Figure $5 \mathrm{c}$ shows the PL of GQDs of varying sizes under $330 \mathrm{~nm}$. The results indicate that the PL intensities of the GQDs with different sizes were different. With the decreasing size of the GQDs, the PL intensity was enhanced. In these four separated GQDs, the GQDs on a dialysis bag of $1000 \mathrm{Da}$ molecular weight have the strongest PL intensity, whereas the GQDs on a dialysis bag of 14,000 Da molecular weight has the weakest PL intensity. The 
PL excitation (PLE) spectrum (Figure 5d) of the GQDs after fixing the emission wavelength was shown at $530 \mathrm{~nm}$, and one of the excitation peaks was shown at $384 \mathrm{~nm}$, which was according to PL results. The PL disintegration curves show the single-exponential feature of the four separated GQDs (Figure S3). The fluorescent lifetime of the GQDs dialyzed with a dialysis bag of 1000 Da molecular weight was shortest to $1.88 \mathrm{~ns}$, which is according to their smallest size.
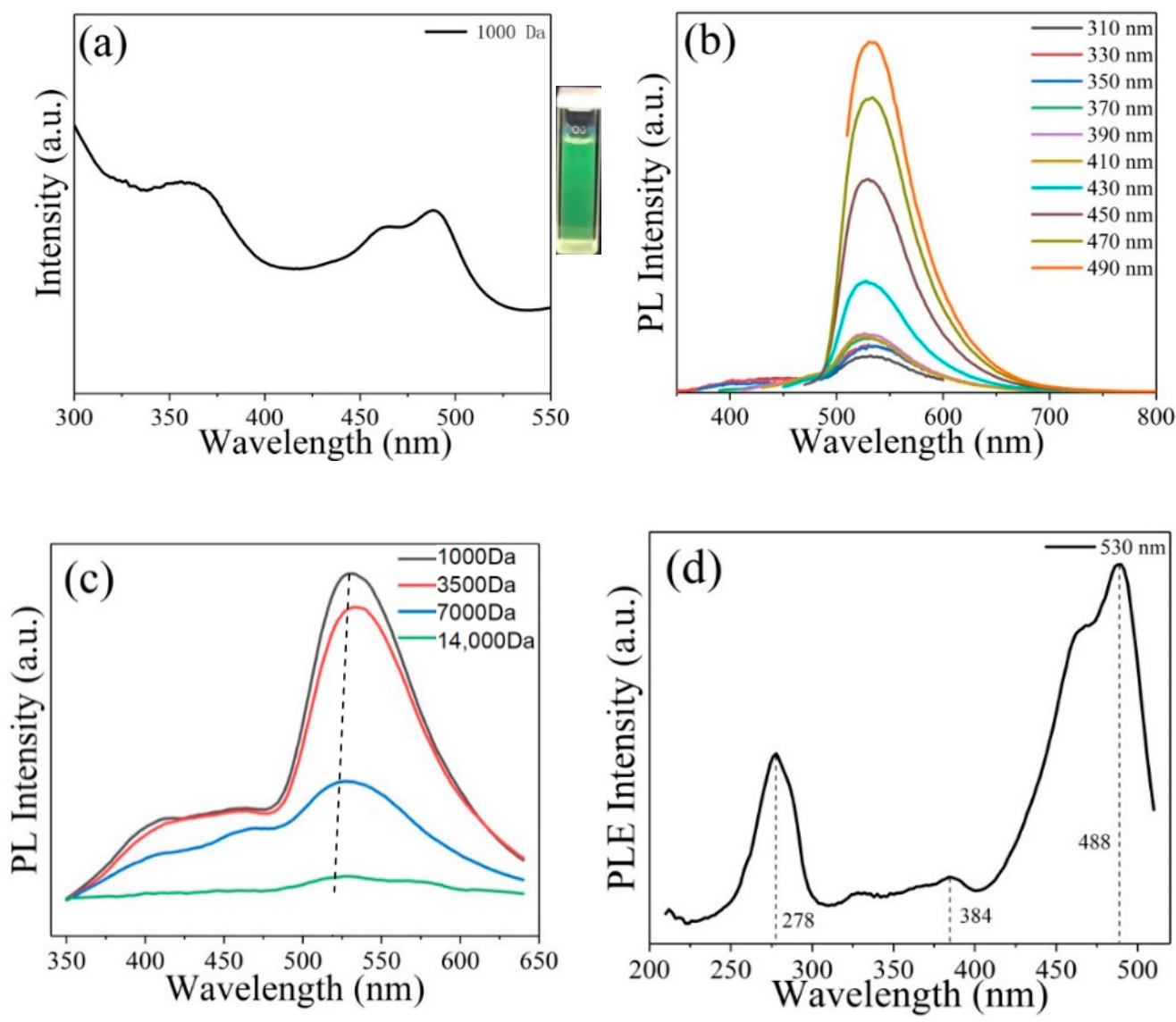

Figure 5. (a) UV-VIS absorption spectrum of the GQDs dialyzed with a dialysis bag of $1000 \mathrm{Da}$ molecular weight (inset, optical photographs of the corresponding samples under excitation with a wavelength of $365 \mathrm{~nm}$ ), (b) PL spectra of the GQDs under excitation with a different wavelength, (c) PL spectra of the four separated GQDs under excitation at $330 \mathrm{~nm}$, (d) PLE spectrum of the GQDs when fixing the emission wavelength at $530 \mathrm{~nm}$.

To further investigate the optical properties of the GQDs obtained by dialysis bags of different molecular weights, the fluorescence QY measurements were calculated by the result of the PL emission intensity and absorption. Table 2 reveals the QY of the four separated GQDs. The results of the samples were calculated using the following formula: $\varphi=\varphi_{\mathrm{r}}\left(\mathrm{I} / \mathrm{I}_{\mathrm{r}}\right)\left(\mathrm{n}^{2} / \mathrm{n}_{\mathrm{r}}^{2}\right)\left(\mathrm{A}_{\mathrm{r}} / \mathrm{A}\right)$ [55], where $\varphi$ represents fluorescence QY, I represents the integrated emission intensity, $\mathrm{n}$ shows the refractive index of the solvent (1.33 of water), $\mathrm{A}$ means optical density, and $r$ stands for reference. The QY of the GQDs of 1000 Da molecular weight reached 0.45 , which is higher than the others, and the result corresponds to that in Figure $5 \mathrm{c}$. Combining the above data and analysis, we speculate that the number of defects contributes to the intensity of luminescence [18]. 
Table 2. QY of the four separated GQDs under excitation at $330 \mathrm{~nm}$ using quinine sulfate as a reference.

\begin{tabular}{ccccc}
\hline Samples & $\begin{array}{c}\text { Integrated Emission } \\
\text { Intensity (I) }\end{array}$ & Abs. (A) & $\begin{array}{c}\text { Refractive Index of } \\
\text { Solvent (n) }\end{array}$ & QY $(\boldsymbol{\varphi})$ \\
\hline Quinine sulfate & 15,644 & 0.109 & 1.33 & $0.54(\mathrm{know})$ \\
$14,000 \mathrm{Da}$ & 397 & 0.128 & 1.33 & 0.02 \\
$7000 \mathrm{Da}$ & 2321 & 0.048 & 1.33 & 0.18 \\
$3500 \mathrm{Da}$ & 4651 & 0.05 & 1.33 & 0.35 \\
$1000 \mathrm{Da}$ & 5047 & 0.042 & 1.33 & 0.45 \\
\hline
\end{tabular}

Figure $5 \mathrm{c}$ shows that the PL emission peaks of the four separated GQDs are slightly red-shifted. We believe that GQDs of different sizes have different band gap widths, resulting in different PL emission peaks. In order to prove this relationship, we performed DFT calculations. The results are illustrated in Figure 6. With the increasing size of the four separated GQDs, the gap of both the armchair- and zigzag-edged GQDs decreases rapidly at first and becomes gentle when the size is greater than $6 \mathrm{~nm}$. When the size is greater than 5 nanometers, the curve begins to become flat. It is known that DFT-GGA methods often underestimate the gap, so we assume that with either an armchair or zigzag edge, the bandgap of GQDs changes lightly depending on their size when the size is greater than $5 \mathrm{~nm}$. It can be seen from this that when the size of the GQD is larger, its band gap becomes smaller, which is consistent with the experimental results. As shown in Figure $5 c$, under excitation at $330 \mathrm{~nm}$, the PL emission peaks of the four separate GQDs are slightly red-shifted as the GQD size increases. As the size of the GQD increases, its energy gap continues to decrease, and photons are more likely to transition, which results in a red shift of the PL emission peak. This result also confirms our conjecture.

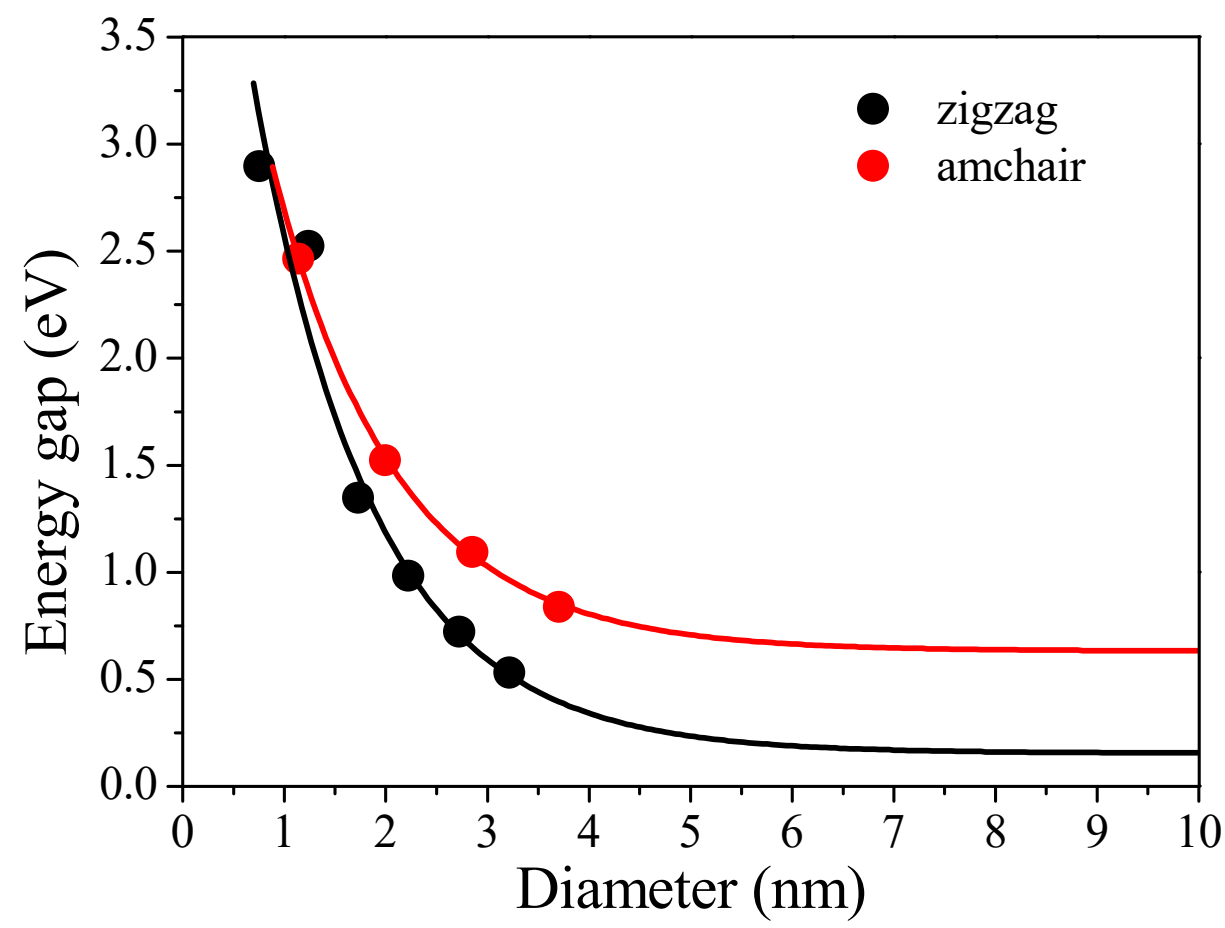

Figure 6. Illustration of the calculated size-dependent electronic gap of the armchair- and zigzagedged GQDs.

\section{Conclusions}

In summary, we synthesized GQDs by a simple one-step hydrothermal method and then obtained different sizes of GQDs using dialysis bags with different molecular weights. The average lateral sizes of the GQDs obtained by dialysis bags of 14,000, 7000, 3500, 
1000 Da molecular weights are about 10.33, 9.33, 8.42, and $6.53 \mathrm{~nm}$, respectively. This indicates that the sizes of the GQDs obtained by dialysis with different molecular weights of dialysis bags are different. Meanwhile, the four separated GQDs displayed different PL intensities. With the decreasing size of the separated GQDs, the intensity of the emission peak becomes much stronger. The GQDs with the smallest size revealed the most energetic PL intensity in the four separated GQDs. DFT calculations show that with a size greater than $6 \mathrm{~nm}$, the bandgap of the GQDs changes slightly. This is consistent with the experimental results.

Supplementary Materials: The following are available online: Figure S1: High-resolution C 1s spectrum of separated GQDs dialyzed with dialysis bags of 14,000 Da (a), $7000 \mathrm{Da}$ (c), and $3500 \mathrm{Da}$ (e) molecular weights. High-resolution O 1s spectrum of separated GQDs dialyzed with dialysis bags of 14,000 Da (b), $7000 \mathrm{Da}(\mathrm{d})$, and $3500 \mathrm{Da}(\mathrm{f})$ molecular weights. Figure S2: UV-VIS absorption spectrum of separated GQDs dialyzed with dialysis bags of 14,000 Da (a), $7000 \mathrm{Da}(\mathrm{b})$, and $3500 \mathrm{Da}$ (c) molecular weights (inset, optical photographs of the corresponding samples under excitation with a wavelength of $365 \mathrm{~nm}$ ). PL spectra of separated GQDs dialyzed with dialysis bags of 14,000 Da (d), $7000 \mathrm{Da}(\mathrm{e})$, and $3500 \mathrm{Da}(\mathrm{f})$ molecular weights under excitation with different wavelengths. Figure S3: Time-resolved PL spectra of the four separated GQDs dialyzed with dialysis bags of 14,000 Da (a), $7000 \mathrm{Da}(\mathrm{b}), 3500 \mathrm{Da}(\mathrm{c})$, and $1000 \mathrm{Da}(\mathrm{d})$ molecular weights.

Author Contributions: Conceptualization, Z.L., F.L., and W.L.; methodology, F.L. and M.L.; software, Y.L. and G.H.; validation, T.T., J.W., and X.L.; formal analysis, X.P.; investigation, W.L.; resources, M.L.; data curation, Z.L. and F.L.; writing—original draft preparation, Z.L. and F.L.; writing-review and editing, X.P. and M.L.; visualization, W.L.; supervision, W.L.; project administration, M.L.; funding acquisition, M.L. All authors have read and agreed to the published version of the manuscript.

Funding: This work was financially supported by the National Natural Science Foundation of China (Nos. 11764011, 51472241, 21571124, and 11664007), China Postdoctoral Science Foundation (No. 2021M692019).

Institutional Review Board Statement: Not applicable.

Informed Consent Statement: Not applicable.

Data Availability Statement: The data can be made available upon reasonable request.

Conflicts of Interest: The authors declare no conflict of interest.

\section{References}

1. Xu, X.Y.; Ray, R.; Gu, Y.L.; Ploehn, H.J.; Gearheart, L.; Raker, K.; Scrivens, W.A. Electrophoretic analysis and purification of fluorescent single-walled carbon nanotube fragments. J. Am. Chem. Soc. 2004, 126, 12736-12737. [CrossRef] [PubMed]

2. Ju, S.Y.; Kopcha, W.P.; Papadimitrakopoulos, F. Brightly Fluorescent Single-Walled Carbon Nanotubes via an Oxygen-Excluding Surfactant Organization. Science 2009, 323, 1319-1323. [CrossRef]

3. Baker, S.N.; Baker, G.A. Luminescent Carbon Nanodots: Emergent Nanolights. Angew. Chem. Int. Ed. 2010, $49,6726-6744$. [CrossRef] [PubMed]

4. Tang, Y.; Rao, L.; Li, Z.; Lu, H.; Yan, C.; Yu, S.; Ding, X.; Yu, B. Rapid synthesis of highly photoluminescent nitrogen-doped carbon quantum dots via a microreactor with foamy copper for the detection of $\mathrm{Hg}^{2+}$ ions. Sens. Actuators B 2018, 258, 637-647. [CrossRef]

5. Murugesan, B.; Sonamuthu, J.; Pandiyan, N.; Pandi, B.; Samayanan, S.; Mahalingam, S. Photoluminescent reduced graphene oxide quantum dots from latex of Calotropis gigantea for metal sensing, radical scavenging, cytotoxicity, and bioimaging in Artemia salina: A greener route. J. Photochem. Photobiol. B Biol. 2018, 178, 371-379. [CrossRef] [PubMed]

6. Eda, G.; Lin, Y.Y.; Mattevi, C.; Yamaguchi, H.; Chen, H.A.; Chen, I.S.; Chen, C.W.; Chhowalla, M. Blue Photoluminescence from Chemically Derived Graphene Oxide. Adv. Mater. 2010, 22, 505-509. [CrossRef]

7. Luo, Y.; Xu, Y.; Li, M.; Sun, L.; Hu, G.; Tang, T.; Wen, J.; Li, X. Tuning the Photoluminescence of Graphene Quantum Dots by Fluorination. J. Nanomater. 2017, 2017, 1-6. [CrossRef]

8. Yan, X.; Cui, X.; Li, B.; Li, L. Large, solution-processable graphene quantum dots as light absorbers for photovoltaics. Nano Lett. 2010, 10, 1869-1873. [CrossRef]

9. Li, L.S.; Yan, X. Colloidal Graphene Quantum Dots. J. Phys. Chem. Lett. 2010, 1, 2572-2576. [CrossRef]

10. Pan, D.; Zhang, J.; Li, Z.; Wu, M. Hydrothermal Route for Cutting Graphene Sheets into Blue-Luminescent Graphene Quantum Dots. Adv. Mater. 2010, 22, 734-738. [CrossRef]

11. Hawrylak, P.; Peeters, F.; Ensslin, K. Carbononics-integrating electronics, photonics and spintronics with graphene quantum dots. Phys. Status Solidi RRL 2016, 10, 11-12. [CrossRef] 
12. Liu, R.; Wu, D.; Feng, X.; Mullen, K. Bottom-up fabrication of photoluminescent graphene quantum dots with uniform morphology. J. Am. Chem. Soc. 2011, 133, 15221-15223. [CrossRef]

13. Kim, S.; Hwang, S.W.; Kim, M.-K.; Shin, D.Y.; Shin, D.H.; Kim, C.O.; Yang, S.B.; Park, J.H.; Hwang, E.; Choi, S.-H.; et al. Choi Anomalous behaviors of visible luminescence from graphene quantum dots: Interplay size and shape. ACS Nano 2012, 6, 8203-8208. [CrossRef]

14. Wang, S.; Li, Z.; Xu, X.; Zhang, G.; Li, Y.; Peng, Q. Amino-Functionalized Graphene Quantum Dots as Cathode Interlayer for Efficient Organic Solar Cells: Quantum Dot Size on Interfacial Modification Ability and Photovoltaic Performance. Adv. Mater. Interfaces 2019, 6, 1801480. [CrossRef]

15. Fei, H.; Ye, R.; Ye, G.; Gong, Y.; Peng, Z.; Fan, X.; Samuel, E.L.G.; Ajayan, P.M.; Tour, J.M. Boron- and nitrogen-doped graphene quantum dots/graphene hybrid nanoplatelets as efficient electrocatalysts for oxygen reduction. ACS Nano 2014, 8, 10837-10843. [CrossRef] [PubMed]

16. Tang, L.; Wang, J.J.; Jia, C.T.; Lv, G.X.; Xu, G.; Li, W.T.; Wang, L.; Zhang, J.Y.; Wu, M.H. Simulated solar driven catalytic degradation of psychiatric drug carbamazepine with binary $\mathrm{BiVO}_{4}$ heterostructures sensitized by graphene quantum dots. Appl. Catal. $B$ Environ. 2017, 205, 587-596. [CrossRef]

17. Yeh, T.F.; Teng, C.Y.; Chen, S.J.; Teng, H. Nitrogen-Doped Graphene Oxide Quantum Dots as Photocatalysts for Overall WaterSplitting under Visible Light Illumination. Adv. Mater. 2014, 26, 3297-3303. [CrossRef] [PubMed]

18. Luo, Y.; Li, M.; Hu, G.; Tang, T.; Wen, J.; Li, X.; Wang, L. Enhanced photocatalytic activity of sulfur-doped graphene quantum dots decorated with $\mathrm{TiO}_{2}$ nanocomposites. Mater. Res. Bull. 2018, 97, 428-435. [CrossRef]

19. Ji, Z.; Dervishi, E.; Doorn, S.; Sykora, M. Size-dependent electronic properties of uniform ensembles of strongly confined graphene quantum dots. J. Phys. Chem. Lett. 2019, 10, 953-959. [CrossRef] [PubMed]

20. Li, Q.; Zhang, S.; Dai, L.; Li, L. Nitrogen-doped colloidal graphene quantum dots and their size-dependent electrocatalytic activity for the oxygen reduction reaction. J. Am. Chem. Soc. 2012, 134, 18932-18935. [CrossRef]

21. Li, F.; Sun, L.; Luo, Y.; Li, M.; Xu, Y.; Hu, G.; Li, X.; Wang, L. Effect of thiophene S on the enhanced ORR electrocatalytic performance of sulfur-doped graphene quantum dot/reduced graphene oxide nanocomposites. RSC Adv. 2018, 8, 19635-19641. [CrossRef]

22. Sun, L.; Luo, Y.; Li, M.; Hu, G.; Xu, Y.; Tang, T.; Wen, J.; Li, X.; Wang, L. Role of Pyridinic-N for Nitrogen-doped graphene quantum dots in oxygen reaction reduction. J. Colloid Interface Sci. 2017, 508, 154-158. [CrossRef]

23. Kim, J.; Lee, B.; Kim, Y.J.; Hwang, S.W. Enhancement of Dye-sensitized Solar Cells Efficiency Using Graphene Quantum Dots as Photoanode. Bull. Korean Chem. Soc. 2019, 40, 56-61. [CrossRef]

24. Sokolov, P.M.; Zvaigzne, M.A.; Krivenkov, V.A.; Litvin, A.P.; Baranov, A.V.; Fedorov, A.V.; Samokhvalov, P.S.; Nabiev, I.R. Graphene-quantum dot hybrid nanostructures with controlled optical and photoelectric properties for solar cell applications. Russ. Chem. Rev. 2019, 88, 370-386. [CrossRef]

25. Gevaerd, A.; Banks, C.E.; Bergamini, M.F.; Marcolino-Junior, L.H. Graphene Quantum Dots Modified Screen-printed Electrodes as Electroanalytical Sensing Platform for Diethylstilbestrol. Electroanalysis 2019, 31, 838-843. [CrossRef]

26. Wang, L.; Li, W.; Wu, B.; Li, Z.; Wang, S.; Liu, Y.; Pan, D.; Wu, M. Facile synthesis of fluorescent graphene quantum dots from coffee grounds for bioimaging and sensing. Chem. Eng. J. 2016, 300, 75-82. [CrossRef]

27. Dong, J.; Wang, K.; Sun, L.; Sun, B.; Yang, M.; Chen, H.; Wang, Y.; Sun, J.; Dong, L. Application of graphene quantum dots for simultaneous fluorescence imaging and tumor-targeted drug delivery. Sens. Actuators B 2018, 256, 616-623. [CrossRef]

28. Wang, L.; Li, W.; Wu, B.; Li, Z.; Pan, D.; Wu, M. Room-temperature synthesis of graphene quantum dots via electron-beam irradiation and their application in cell imaging. Chem. Eng. J. 2017, 309, 374-380. [CrossRef]

29. Wang, L.; Wu, B.; Li, W.; Li, Z.; Zhan, J.; Geng, B.; Wang, S.; Pan, D.; Wu, M. Industrial production of ultra-stable sulfonated graphene quantum dots for Golgi apparatus imaging. J. Mater. Chem. B 2017, 5, 5355-5361. [CrossRef]

30. Wang, L.; Li, W.; Li, M.; Su, Q.; Li, Z.; Pan, D.; Wu, M. Ultrastable Amine, Sulfo Cofunctionalized Graphene Quantum Dots with High Two-Photon Fluorescence for Cellular Imaging. ACS Sustain. Chem. Eng. 2018, 6, 4711-4716. [CrossRef]

31. Wang, L.; Wu, B.; Li, W.; Wang, S.; Li, Z.; Li, M.; Pan, D.; Wu, M. Amphiphilic Graphene Quantum Dots as Self-Targeted Fluorescence Probes for Cell Nucleus Imaging. Adv. Biosys. 2018, 2, 1700191. [CrossRef]

32. Pan, D.; Guo, L.; Zhang, J.; Xi, C.; Xue, Q.; Huang, H.; Li, J.; Zhang, Z.; Yu, W.; Chen, Z.; et al. Cutting sp ${ }^{2}$ clusters in graphene sheets into colloidal graphene quantum dots with strong green fluorescence. J. Mater. Chem. 2012, 22, 3314-3318. [CrossRef]

33. Dong, Y.; Chen, C.; Zheng, X.; Gao, L.; Cui, Z.; Yang, H.; Guo, C.; Chi, Y.; Li, C.M. One-step and high yield simultaneous preparation of single- and multi-layer graphene quantum dots from CX-72 carbon black. J. Mater. Chem. 2012, 22, 8764-8766. [CrossRef]

34. Li, W.; Li, M.; Liu, Y.; Pan, D.; Li, Z.; Wang, L.; Wu, M. Three Minute Ultrarapid Microwave-Assisted Synthesis of Bright Fluorescent Graphene Quantum Dots for Live Cell Staining and White LEDs. ACS Appl. Nano Mater. 2018, 1, 1623-1630. [CrossRef]

35. Li, L.; Wu, G.; Yang, G.; Peng, J.; Zhao, J.; Zhu, J.J. Focusing on luminescent graphene quantum dots: Current status and future perspectives. Nanoscale 2013, 5, 4015-4039. [CrossRef] [PubMed]

36. Qi, C.; Chentian, S.; Chunfeng, Z.; Songyang, P.; Rui, W.; Xuewei, W.; Xiaoyong, W.; Fei, X.; Dengyu, P.; Min, X. Magnetic enhancement of photoluminescence from blue-luminescent graphene quantum dots. Appl. Phys. Lett. 2016, 108, 1-5.

37. Dong, Y.; Shao, J.; Chen, C.; Li, H.; Wang, R.; Chi, Y.; Lin, X.; Chen, G. Blue luminescent graphene quantum dots and graphene oxide prepared by tuning the carbonization degree of citric acid. Carbon 2012, 50, 4738-4743. [CrossRef]

38. Wang, K.; Dong, J.; Sun, L.; Chen, H.; Wang, Y.; Wang, C.; Dong, L. Effects of elemental doping on the photoluminescence properties of graphene quantum dots. RSC Adv. 2016, 6, 91225-91232. [CrossRef] 
39. Gu, S.; Hsieh, C.T.; Tsai, Y.Y.; Ashraf Gandomi, Y.; Yeom, S.; Kihm, K.D.; Fu, C.C.; Juang, R.S. Sulfur and Nitrogen Co-Doped Graphene Quantum Dots as a Fluorescent Quenching Probe for Highly Sensitive Detection toward Mercury Ions. ACS Appl. Nano Mater. 2019, 2, 790-798. [CrossRef]

40. Li, X.; Lau, S.P.; Tang, L.; Ji, R.; Yang, P. Multicolour light emission from chlorine-doped graphene quantum dots. J. Mater. Chem. C 2013, 1, 7308-7313. [CrossRef]

41. Wang, L.; Wang, Y.; Xu, T.; Liao, H.; Yao, C.; Liu, Y.; Li, Z.; Chen, Z.; Pan, D.; Sun, L.; et al. Gram-scale synthesis of single-crystalline graphene quantum dots with superior optical properties. Nat. Commun. 2014, 5, 5357-5365. [CrossRef]

42. Kresse, G. Ab initio molecular dynamics for liquid metals. J. Non-Cryst. Solids 1995, 192-193, 222-229. [CrossRef]

43. Kresse, G.; Furthmuller, J. Efficient iterative schemes for ab initio total-energy calculations using a plane-wave basis set. Phys. Rev. B Condens. Matter. 1996, 54, 11169-11186. [CrossRef]

44. Kresse, G.; Joubert, D. From ultrasoft pseudopotentials to the projector augmented-wave method. Phys. Rev. B 1999, 59, 1758-1775. [CrossRef]

45. Blöchl, P.E. Projector augmented-wave method. Phys. Rev. B 1994, 50, 17953-17979. [CrossRef]

46. Perdew, J.P.; Burke, K.; Ernzerhof, M. Generalized Gradient Approximation Made Simple. Phys. Rev. Lett. 1996, 77, 3865-3868. [CrossRef] [PubMed]

47. Ding, Z.; Li, F.; Wen, J.; Wang, X.; Sun, R. Gram-scale synthesis of single-crystalline graphene quantum dots derived from lignin biomass. Green Chem. 2018, 20, 1383-1390. [CrossRef]

48. Peng, J.; Gao, W.; Gupta, B.K.; Liu, Z.; Romero-Aburto, R.; Ge, L.; Song, L.; Alemany, L.B.; Zhan, X.; Gao, G.; et al. Graphene Quantum Dots Derived from Carbon Fibers. Nano Lett. 2012, 12, 844-849. [CrossRef] [PubMed]

49. Chien, C.T.; Li, S.S.; Lai, W.J.; Yeh, Y.C.; Chen, H.A.; Chen, I.S.; Chen, L.C.; Chen, K.H.; Nemoto, T.; Isoda, S.; et al. Tunable photoluminescence from graphene oxide. Angew. Chem. Int. Ed. 2012, 51, 6662-6666. [CrossRef]

50. Li, J.L.; Bao, H.C.; Hou, X.L.; Sun, L.; Wang, X.G.; Gu, M. Graphene Oxide Nanoparticles as a Nonbleaching Optical Probe for Two-Photon Luminescence Imaging and Cell Therapy. Angew. Chem. Int. Ed. 2012, 51, 1830-1834. [CrossRef]

51. Xu, Q.; Zhou, Q.; Hua, Z.; Xue, Q.; Zhang, C.; Wang, X.; Pan, D.; Xiao, M. Single-Particle Spectroscopic Measurements of Fluorescent Graphene Quantum Dots. ACS Nano 2013, 7, 10654-10661. [CrossRef] [PubMed]

52. Zhu, Z.; Ma, J.; Wang, Z.; Mu, C.; Fan, Z.; Du, L.; Bai, Y.; Fan, L.; Yan, H.; Phillips, D.L.; et al. Efficiency Enhancement of Perovskite Solar Cells through Fast Electron Extraction: The Role of Graphene Quantum Dots. J. Am. Chem. Soc. 2014, 136, $3760-3763$. [CrossRef] [PubMed]

53. Liu, M.L.; Yang, L.; Li, R.S.; Chen, B.B.; Liu, H.; Huang, C.Z. Large-scale simultaneous synthesis of highly photoluminescent green amorphous carbon nanodots and yellow crystalline graphene quantum dots at room temperature. Green Chem. 2017, 19, 3611-3617. [CrossRef]

54. Suryawanshi, A.; Biswal, M.; Mhamane, D.; Gokhale, R.; Patil, S.; Guin, D.; Ogale, S. Large scale synthesis of graphene quantum dots (GQDs) from waste biomass and their use as an efficient and selective photoluminescence on-off-on probe for $\mathrm{Ag}^{+}$ions. Nanoscale 2014, 6, 11664-11670. [CrossRef]

55. Li, M.; Wu, W.; Ren, W.; Cheng, H.M.; Tang, N.; Zhong, W.; Du, Y. Synthesis and upconversion luminescence of N-doped graphene quantum dots. Appl. Phys. Lett. 2012, 101, 103107. [CrossRef] 